\title{
Do Enfisema Subcutâneo ao Enfisema das Escleras
}

\section{From Subcutaneous Emphysema to Emphysema of Sclera}

Nuno Oliveira', Hugo Queimado², Luís Ramos², Francisco Rodrigues²

PALAVRAS-CHAVE: Enfisema Subcutâneo; Esclera/lesões; Pneumotórax

KEYWORDS: Pneumothorax; Sclera/injuries; Subcutaneous Emphysema

Homem, de 55 anos, recorreu ao serviço de urgência após queda de 1,5 m de altura, traumatismo craniano, sem perda de consciência e trauma dorsal esquerdo. Negava dispneia. À observação: eupneico em ar ambiente, sem alterações à auscultação pulmonar; com dor na palpação da grelha costal esquerda; sem evidência de enfisema subcutâneo.

Realizou radiograma do tórax e grelha costal esquerda que não revelou hemotórax, pneumotórax ou fraturas de arcos costais. No radiograma da grelha costal observaram-se sinais sugestivos de enfisema subcutâneo e imagem compatível com o músculo grande peitoral esquerdo (Fig. 1). O estudo tomodensitométrico do crânio revelou enfisema subcutâneo na região temporal, bilateralmente.

À reobservação: enfisema subcutâneo na região dos músculos peitorais, cervical, face e região temporal.
Realizou tomografia computorizada do tórax: pequeno pneumotórax à esquerda, pneumomediastino, enfisema subcutâneo desde o músculo grande peitoral até à região cervical; ausência de aspetos compatíveis com fratura de arcos costais.

Foi realizada drenagem torácica no quinto espaço intercostal esquerdo. Apresentou evolução globalmente favorável, mas no primeiro dia de internamento ainda com progressão do enfisema que se estendeu até às escleras (Fig. 2).

O trauma torácico sem fratura de arcos costais pode originar pneumotórax e este nem sempre é visível na radiografia do tórax. Por outro lado, enfisema subcutâneo implica laceração do pulmão e pleura, pelo que deve motivar a continuação da investigação e avaliação da necessidade de drenagem torácica. ${ }^{1}$ 


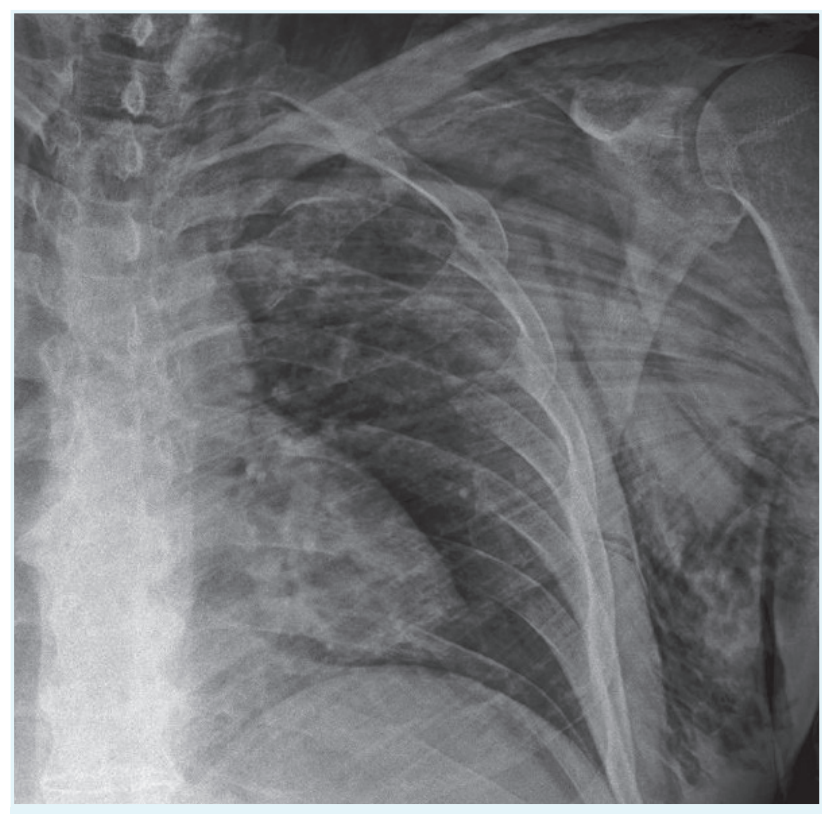

FIGURA 1. Enfisema subcutâneo - radiografia grelha costal esquerda onde é possível visualizar o músculo grande peitoral esquerdo.

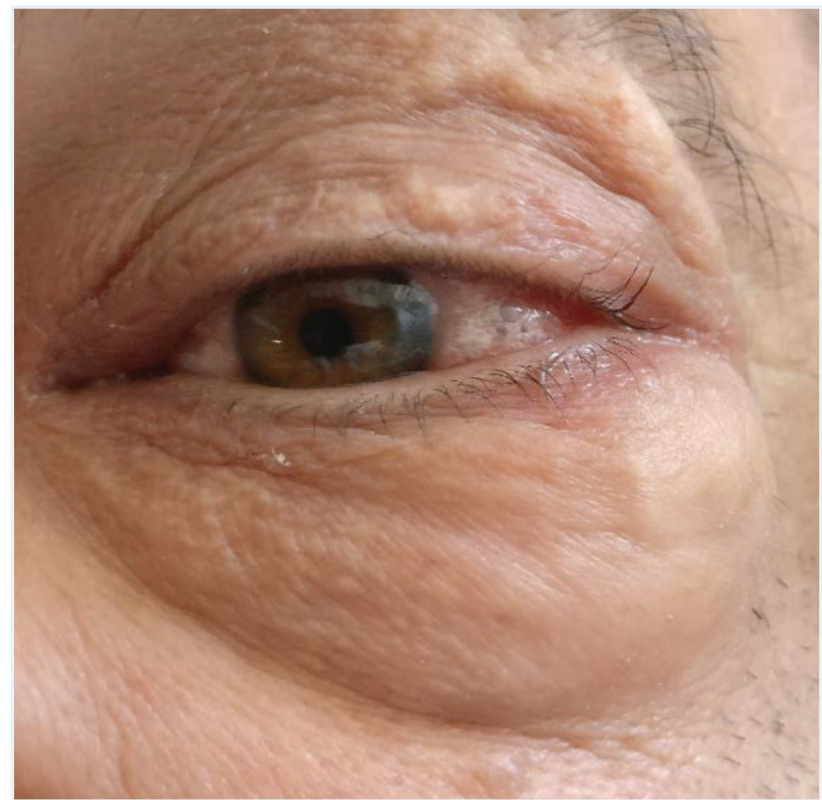

FIGURA 2. Enfisema subcutâneo da pálpebra inferior esquerda e esclera.
CONFLITOS DE INTERESSE: Os autores declaram não ter qualquer conflito de interesse na realização do presente trabalho.

FONTES DE FINANCIAMENTO: Não houve qualquer fonte de financiamento na realização do presente trabalho.

CONFIDENCIALIDADE DOS DADOS: Os autores declaram ter seguido os protocolos da sua instituição acerca da publicação dos dados de doentes.

PROTEÇÃO DE PESSOAS E ANIMAIS: Os autores declaram que os procedimentos seguidos na elaboração do presente trabalho estão em conformidade com as normas das comissões de investigação clínica e de ética, bem como da declaração de Helsínquia e da Associação Médica Mundial.

CONFLICTS OF INTEREST: The authors declare that they have no conflicts of interest.

FINANCIAL SUPPORT: This work has not received any contribution, grant or scholarship.

CONFIDENTIALITY OF DATA: The authors declare that they have followed the protocols of their work center on the publication of data from patients.

PROTECTION OF HUMAN AND ANIMAL SUBJECTS: The authors declare that the procedures followed were in accordance with the regulations of the relevant clinical research ethics committee and with those of the Code of Ethics of the World Medical Association (Declaration of Helsinki).

\section{REFERÊNCIAS}

1. McKnight CL, Burns B. Pneumothorax. In: StatPearls [Internet]. Treasure Island: StatPearls Publishing; 2018. [Accessed Jan 2018] Available from: https://www.ncbi.nlm.nih.gov/books/NBK441885/. 